\title{
A Decomposition Approach for Combined Heuristic and Differential Evolution Method for the Reactive Power Problem
}

\author{
B. Bhattacharyya ${ }^{1}$ and S.K. Goswami ${ }^{2}$ \\ ${ }^{1}$ Dept. of Electrical Engineering, NIT, Durgapur 713209, India \\ ${ }^{2}$ Dept. of Electrical Engineering, Jadavpur University, Kolkata 700032, India \\ biplabrec@yahoo.com, skgoswami_ju@yahoo.co.in
}

\begin{abstract}
The author in the present paper has attempted a variable decomposition approach. All the variables of the reactive power planning optimization do not involve cost. Those involving costs are treated as planning variables and the variables having no cost involvement are treated separately as the dispatch variables. Solution approaches are also designed separately for the two types of variables and a mixed heuristic and evolutionary strategy has been developed. As the number of variables in the evolutionary technique thus decreases, the solution becomes faster.
\end{abstract}

Keywords: Heuristics, Evolutionary techniques, Planning, Dispatch.

\section{Introduction}

In this paper, the main concern is proper planning and co-ordination of control variables which are either transformer tap changers, shunt capacitors, Generators reactive VAr's in an interconnected power system such that real power loss becomes minimum. The problem of reactive power planning in a power system can be shown to be a combinatorial optimization problem and number of methods have been proposed to solve the problem Reactive power planning tool was described in [1]. Simulated Annealing technique [2,3] is applied for the capacitor placement problem. Fuzzy logic, found it's application for handling reactive power problem in [4-6]. Expert system [7], and AI method [8] is also used for solving the reactive power problem. Heuristics and approximate reasoning approach was used to get the solution of reactive power problem in [9-12]. Genetic Algorithm [13-20] is used as an optimization technique for capacitor placement and also for solving reactive power planning and dispatch problem. Evolutionary programming, Evolutionary strategies [21-27] were applied for reactive power problem. Particle Swarm optimization (PSO) [28] is used as a technique to deal reactive power problem. Differential Evolution and the Hybrid Evolutionary approaches [29-34] are recent trends to handle reactive power optimization problems. In the present paper, the authors propose a new approach to the solution of the reactive power problem based on heuristics for the capacitor placements and Differential Evolution (DE) 
method for controlling reactive generations of Generators and transformer tap positions of an inter connected power system. Shunt capacitors which is treated as planning variable are installed at candidate buses using heuristic approach considering loss sensitivity at that bus. Differential Evolution technique is then applied for optimal setting of transformer tap positions and reactive Var's Generated by the Generator's . The results obtained by each of this mixed heuristics and Differential Evolution technique is then compared with the results obtained by using each of the Evolutionary (GA,PSO and DE) methods.

\section{The Proposed Approach}

The method has been developed for solving the reactive power planning problem though it may be used for the dispatch problem as well. Installation of the generators and tap changing transformers in a power system require considerations of the aspects beyond the reach of the reactive power optimization problem. On the other hand, the decision of installing new capacitors is solely guided by the reactive power considerations. As the capacitor installations involve costs, it is expected that the decision for the installations of new capacitors will be taken after the best possible utilization of the existing sources only. This gives rise to the idea that capacitor installation problem has to be solved after solving the reactive power dispatch problem for the generators and the tap changing transformers only. In such a case the capacitor installation problem has to solved separately so as to minimize the additional cost to be incurred in the new capacitors. On the other hand, treatment of the complete problem simultaneously, as in conventional way, will demand unnecessary searches requiring long time to generate the optimal solution. The above stated idea motivated the development of a heuristic technique for the solution of the capacitor installation problem and an evolutionary approach for solving the generator and tap changer dispatch problem.

\subsection{The Heuristic Technique for the Capacitor Installation Problem}

The installation of a new capacitor is justified by two related responses of the systems. The cost reduction due to reduced power loss and the improvement of the voltage profile.

Given the loss equation of a power system

$P_{l o s s}=\sum_{k} v_{i}^{2}+v_{j}^{2}-2 v_{i} v_{j} \cos \delta_{i j}$, and assuming that change in the Var generations has negligible effect on the voltage phase angle such that voltage magnitudes only will be changed, loss sensitivity with respect to node voltages may be used to judge where new sources are to be introduced or old sources are to be made richer.

For changes in the bus voltages, incremental change in the power loss is given by

$$
\Delta P_{\text {loss }}=\left[\frac{\partial P_{\text {loss }}}{\partial v_{1}} \frac{\partial P_{\text {loss }}}{\partial v_{2}} \ldots \ldots . . . \frac{\partial P_{\text {loss }}}{\partial v_{n}}\right] \quad\left[\Delta v_{1} . \Delta v_{2} \ldots . . \Delta v_{n}\right]^{T}
$$


The implication of the above relation is that loss reduction can be achieved by increasing the voltages at those nodes where loss sensitivity to voltage has a negative value and reducing the voltages of those nodes where loss sensitivity value is positive. Maximum reduction in the loss is possible where the product $\frac{\partial P_{\text {loss }}}{\partial v_{i}} \cdot \Delta v_{i}$ is most negative and this node should first be selected for additional Var support. While $\frac{\partial P_{\text {loss }}}{\partial v_{i}}$ can be determined by putting the current values of the node voltages and phase angles in the relation $\frac{\partial P_{l o s s}}{\partial v_{i}}=\sum_{k} 2 v_{i}-2 v_{j} \cos \delta_{i j}$, where $k$ include all lines incident to node $-\mathrm{i}$, problem arises in getting a value for $\Delta \mathrm{v}_{\mathrm{i}}$. One way to overcome the problem may be to know the maximum possible reduction in loss by adjusting the voltage of node $\mathrm{i}$. Thus, in the present work $\Delta \mathrm{v}_{\mathrm{i}}$ is computed as $\Delta v_{i}=v_{i}^{\max }-v_{i}$ or, $\Delta v_{i}=v_{i}^{\min }-v_{i}$ depending upon the sign of the loss sensitivity. $v_{i}$ in the above is the known voltage at node $i$.

The above stated procedure for selecting the node for additional Var generation may work without any problem in case of a dispatch problem. In the planning problem, however, simply reducing the loss may not reduce the overall cost of the system as reduction has to be achieved by paying for additional capacitors to be installed. Moreover, operational constraint for system voltage also has to be maintained. To be on the safe side, therefore, it is decided to select that node as the first candidate for capacitor installation where the product of $\frac{\partial P_{\text {loss }}}{\partial v_{i}} \cdot \Delta v_{i}$ is most negative and at the same time voltage is outside the permissible lower and upper limits. The amount of capacitor Var addition however has to be justified before taking an installation decision. The verification of cost reduction requires a load flow to be performed. A decoupled load flow is used here. A further gain in solution speed of the load flow is achieved by recognizing the fact that, addition of Var generation will not change the active power flow pattern. Thus, after the addition of the Var source only the Q-equation of the fast decoupled load flow has to be solved in order to assess the cost benefit. Still greater reduction in solution time is achieved by modeling the capacitor as a constant Var source. This eliminates the necessity of updating the B" matrix and simple forward and backward substitutions only serve the purpose.

The heuristic algorithm for capacitor location identification is as given below:

1. Determine the loss sensitivities at all the nodes of the system.

2. Determine maximum possible voltage adjustments

$$
\Delta v_{i}=v^{\lim i t}-v_{i}
$$

3. Determine the product $\frac{\partial P_{\text {loss }}}{\partial v_{i}} \cdot \Delta v_{i}, \mathrm{i}=1, \ldots \ldots \mathrm{n}$. 
4. Identify the nodes having a negative value of the product.

5. Order the nodes with decreasing values of the product.

6. Select the first node of the list as the capacitor location.

7. Apply the minimum size of capacitor, at the selected location.

8. Perform only the Q-solution of the decoupled load flow.

9. Determine the loss reduction.

10. Compare with the capacitor cost.

11. If cost reduction is possible, install the capacitor and go to step -1 . Otherwise go to the next step.

12. All nodes in the list exhausted? If yes go to step 14. Otherwise go to the next step.

13. Select the next node in the list as the capacitor location and go to Step 7.

14. End of the heuristic step 7.

\subsection{The Evolutionary Solution}

As already mentioned, the evolutionary approach is used in this algorithm to know the optimum dispatch only. For this, capacitors selected by the heuristic algorithm are assumed to be fixed in the evolutionary process and the generator reactive outputs and the tap changer ratios are used as variables. The evolutionary algorithm such as DE( Differential Evolution) then works in the usual manner. It is to be mentioned here that for the load flows to be performed during the execution of the evolutionary algorithms, capacitors need not be modeled as constant Q-source. Rather an admittance model this time is preferred to have a better result.

\subsection{The Mixed Heuristic and Evolutionary Algorithm}

Because of the sequential solutions of the two part of the problem, a one step solution will seldom be the optimum. An iterative approach is therefore necessary. The complete solution algorithm is as given in the flowchart below:

\section{Application Results}

The proposed mixed heuristic and differential evolution approach has been applied to solve the reactive optimization problems of IEEE 14 and 30 bus test systems.

In IEEE 14 bus system the first three elements of the string are for transformer tap position the next four positions are for Generator Var sources and as the weak buses are selected by heuristics, the string length has reduced to seven.

Transformer taps are in line 8,9 and 11 of the IEEE 14 bus system, since Bus number 2, 3, 6, 8 are PV buses, generator vars are controlled at these four buses. Heuristically 10th , 13th and 14th buses are determined as weak buses. Hence Shunt capacitors are installed at these locations. Transformer taps are in line 11, 12, 15 and 36 
of the IEEE 30 bus, hence 1st four positions are assigned for transformer taps in the string, 5th to 9th position are kept for generator reactive VAR sources as bus 2, 5, 8, 11 and 13 are the PV buses of the 30 bus system. So string length is nine and hence string length is reduced in comparison to that considered in chapter three. By Heuristic analysis 21st, 26th and 30th buses are found as candidate buses for installation of shunt capacitors. Table 1 - shows the result obtained by Heuristic - DE method and comparison of this method with that of GA, PSO and DE method for IEEE 14 and IEEE 30 bus.

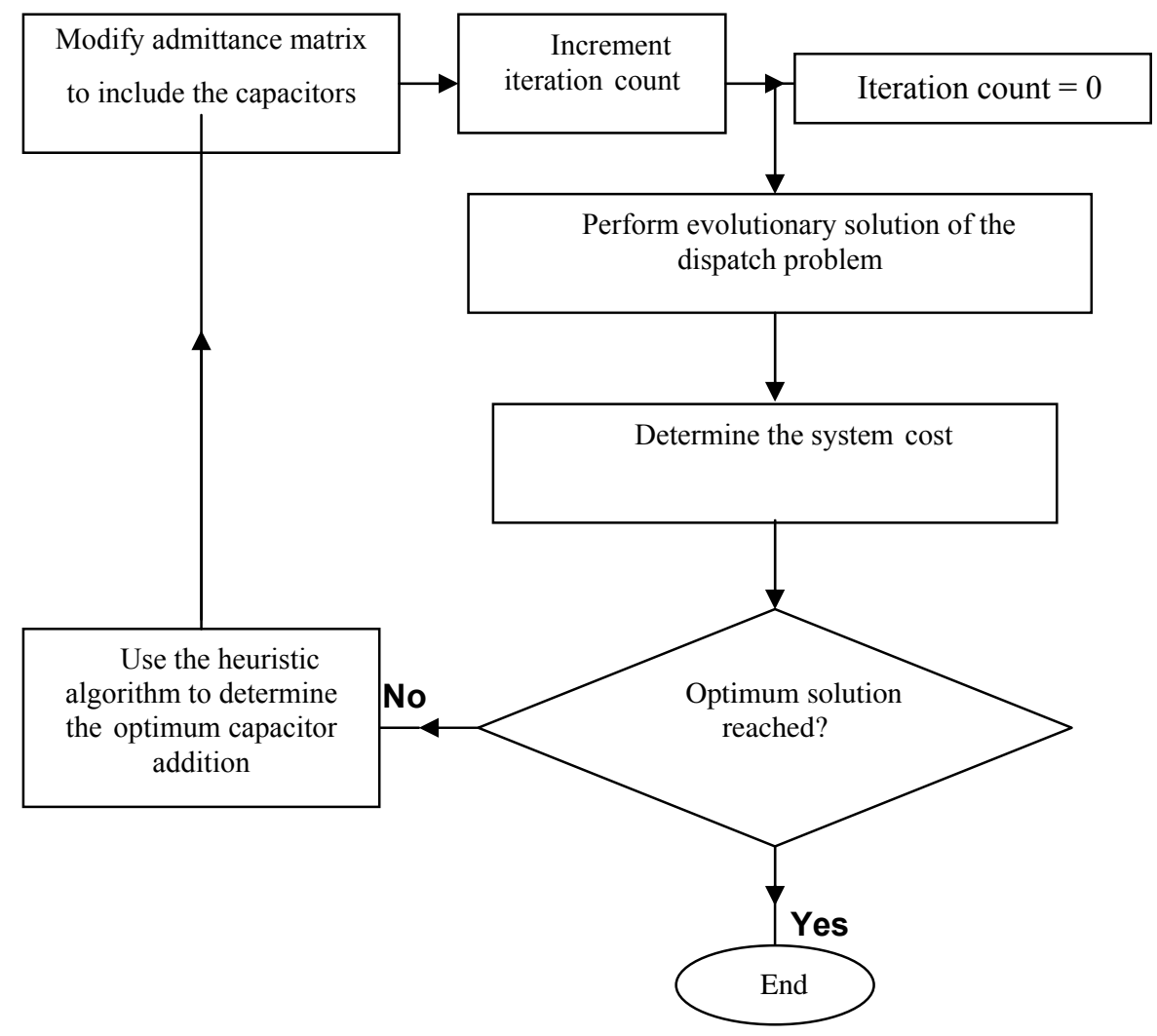

As already mentioned, the evolutionary approach is used in this algorithm to know the optimum dispatch only. For this, capacitors selected by the heuristic algorithm are assumed to be fixed in the evolutionary process and the generator reactive outputs and the tap changer ratios are used as variables. The evolutionary algorithm such as DE (Differential Evolution) then works in the usual manner. It is to be mentioned here that for the load flows to be performed during the execution of the evolutionary algorithms, capacitors need not be modeled as constant Q-source. Rather an admittance model this time is preferred to have a better result. 
Table 1. Results of the Heuristic- DE \& other Evolutionary algorithms : Planning Problem. (Note: Numbers within the parenthesis indicate the buses or branches where the devices are connected)

\begin{tabular}{|c|c|c|c|c|}
\hline $\begin{array}{l}\text { Test } \\
\text { System }\end{array}$ & Heuristic - DE & GA & PSO & DE \\
\hline \multirow{5}{*}{$\begin{array}{l}\text { IEEE } 14 \\
\text { Bus }\end{array}$} & $\begin{array}{l}\text { Optimum } \\
\text { Solution }\end{array}$ & $\begin{array}{l}\text { Optimum } \\
\text { Solution }\end{array}$ & $\begin{array}{l}\text { Optimum } \\
\text { Solution }\end{array}$ & Optimum Solution \\
\hline & $\begin{array}{l}\text { Cost in } \$:- \\
6.9441 \times 106 \\
\end{array}$ & $\begin{array}{l}\text { Cost in } \$:- \\
6.9493 \times 106 \\
\end{array}$ & $\begin{array}{l}\text { Cost in } \$:- \\
6.9477 \times 106 \\
\end{array}$ & $\begin{array}{l}\text { Cost in } \$:- \\
6.9470 \times 106 \\
\end{array}$ \\
\hline & $\begin{array}{l}\text { Variable } \\
\text { Values:- } \\
\text { Generator:- }\end{array}$ & $\begin{array}{l}\text { Variable values:- } \\
\text { Generator:- }\end{array}$ & $\begin{array}{l}\text { Variable } \\
\text { Values:- } \\
\text { Generator:- }\end{array}$ & $\begin{array}{l}\text { Variable Values:- } \\
\text { Generator:- }\end{array}$ \\
\hline & $0.3109 \quad 0.2514$ & $0.3221 \quad 0.2532$ & $0.3082 \quad 0.2487$ & $0.3135 \quad 0.2499$ \\
\hline & $\begin{array}{l}0.2259 \quad 0.0421 \\
\text { tap position:- } \\
0.95680 .950 .95 \\
\text { Shunt values:- } \\
0.006(7) \\
0.03(10) \\
0.072(13) \\
0.048(14) \\
\end{array}$ & $\begin{array}{l}0.1650 \quad 0.1161 \\
\text { tap position:- } \\
0.950 .950 .95 \\
\text { Shunt values:- } \\
0.0461(14) \\
0.0632(13) \\
0.0203(12)\end{array}$ & $\begin{array}{l}0.24 \quad 0.1014 \\
\text { tap position; } \\
0.950 .950 .95 \\
\text { Shunt values:- } \\
0.0476(14) \\
0.0519(13) \\
\quad 0(12)\end{array}$ & $\begin{array}{l}0.23180 .0907 \\
\text { tap position:- } \\
0.950 .950 .95 \\
\text { Shunt values:- } \\
0.0477(14) \\
0.0513(13) \\
0.0141(12)\end{array}$ \\
\hline \multirow{11}{*}{$\begin{array}{l}\text { IEEE } 30 \\
\text { Bus }\end{array}$} & $\begin{array}{l}\text { Optimum } \\
\text { Solution }\end{array}$ & $\begin{array}{l}\text { Optimum } \\
\text { Solution }\end{array}$ & $\begin{array}{l}\text { Optimum } \\
\text { Solution }\end{array}$ & Optimum Solution \\
\hline & $\begin{array}{l}\text { Cost in } \$:- \\
3.5852 \times 106 \\
\end{array}$ & $\begin{array}{l}\text { Cost in } \$:- \\
3.5899 \times 106 \\
\end{array}$ & $\begin{array}{l}\text { Cost in } \$:- \\
3.6029 \times 106 \\
\end{array}$ & $\begin{array}{l}\text { Cost in } \$:- \\
3.5877 \times 106 \\
\end{array}$ \\
\hline & $\begin{array}{l}\text { Variable } \\
\text { Values:- } \\
\text { Generator:- }\end{array}$ & $\begin{array}{l}\text { Variable Values:- } \\
\text { Generator:- }\end{array}$ & $\begin{array}{l}\text { Variable } \\
\text { Values:- } \\
\text { Generator:- }\end{array}$ & $\begin{array}{l}\text { Variable Values:- } \\
\text { Generator:- }\end{array}$ \\
\hline & $\begin{array}{ll}0.1513 & 0.2561\end{array}$ & $\begin{array}{ll}0.1371 & 0.2603\end{array}$ & $\begin{array}{lll}0.1818 & 0.2721\end{array}$ & $0.1572 \quad 0.2523$ \\
\hline & $0.22629 \quad 0.0382$ & $\begin{array}{ll}0.2575 & 0.0887\end{array}$ & $0.3466 \quad 0.1$ & $0.2495 \quad 0.432$ \\
\hline & $\begin{array}{l}0.2514 \\
\text { tap position:- }\end{array}$ & $\begin{array}{l}0.2061 \\
\text { tap position:- }\end{array}$ & $\begin{array}{l}0.2639 \\
\text { tap position; }\end{array}$ & $\begin{array}{l}0.2366 \\
\text { tap position:- }\end{array}$ \\
\hline & $\begin{array}{llll}0.9 & 0.9 & 0.9 & 0.9\end{array}$ & $\begin{array}{ll}0.9084 & 0.9007 \\
0.9101 & 0.9001\end{array}$ & $\begin{array}{ll}0.9 & 0.9104 \\
0.9090 & 0.9\end{array}$ & $\begin{array}{llll}0.9 & 0.9 & 0.9 & 0.9\end{array}$ \\
\hline & $\begin{array}{l}\text { Shunt values:- } \\
0.036(21)\end{array}$ & $\begin{array}{l}\text { Shunt values:- } \\
0.0136(29)\end{array}$ & $\begin{array}{l}\text { Shunt values:- } \\
0.0204(29)\end{array}$ & $\begin{array}{l}\text { Shunt values:- } \\
0.0140(29)\end{array}$ \\
\hline & $0.036(26)$ & $0.0394(20)$ & $0.0636(20)$ & $0.0455(20)$ \\
\hline & $0.04830)$ & $0.0232(30)$ & $0.0169(30)$ & $0.0307(30)$ \\
\hline & & $0.0245(14)$ & $0(14)$ & $0.0169(14)$ \\
\hline
\end{tabular}

\section{Conclusion}

Here, it is observed that if heuristic approach is used for shunt capacitor placement purpose and then differential evolution technique is continued for solving reactive power planning problem, considerable improvement is noticed. So this approach could be a new method for solving reactive power optimization problem. This approach is 
used for finding the solution of the reactive power problem by using variable decomposition technique in the sense that some of the power system control variable is treated as planning variable and the rest of the variables those does not incorporate cost in the objective function are treated as dispatch variables.

\section{References}

1. Losi, A., Rossi, F., Russo, M., Verde, P.: A new tool for reactive power planning. IEE Proc, Genr, Transm, Distrib. 1140(4), 256-262 (1993)

2. Chiang, H.D., Wang, J.C., Cockings, O., Shin, H.D.: Optimal Capacitor Placements in Distribution Systems: Part 1: A new Formulation and the Overall Problem. IEEE Trans, power Delivery 5(2), 634-642 (1990)

3. Chiang, H.D., Wang, J.C., Cockings, O., Shin, H.D.: Optimal Capacitor Placements in Distribution Systems: Part 2: A new Formulation and the Overall Problem. IEEE Trans, power Delivery 5(2), 643-649 (1990)

4. Rahaman, K.H.A., Shahidehpour, S.M.: A Fuzzy Based Optimal Reactive Power Control. IEEE Trans, Power Syst. 8(2), 66-668 (1993)

5. Rahaman, K.H.A., Shahidehpour, S.M.: Reactive Power Optimization Using Fuzzy Load Representation. IEEE Trans, Power Syst. 9(2), 898-905 (1994)

6. Chen, Y.L.: An interactive Fuzzy - Norm satisfying method for Multiobjective Reactive power sources planning. IEEE Trans on Power Syst. 15(3), 1154-1160 (2000)

7. Jwo, W.S., Liu, C.W., Liu, C.C., Hsiao, Y.T.: Hybrid expert and simulated annealing approach to optimal reactive power planning. IEE Proc, Genr, Transm, Distrib. 142(4), 381385 (1995)

8. Rahaman, K.H.A., Shahidehpour, S.M., Daneshdoost, M.: AI Approach to Optimal Var control with Fuzzy Reactive Load. IEEE Trans, Power Syst. 10(1), 88-97 (1995)

9. Yokoyama, R., Niimura, T., Nakanishi, Y.: A coordinated Control Of Voltage And Reactive Power By Heuristic Modelling And Approximate Reasoning. IEEE Trans, Power Syst. 8(2), 636-670 (1993)

10. Mantovani, J.R.S., Garcia, A.V.: A heuristic method for reactive power planning. IEEE Trans on Power Syst. 11(1), 68-74 (1996)

11. Chis, M., Salama, M.M.A., Jayaram, S.: Capacitor Placement In Distribution Systems Using Heuristic Search Strategies. IEE Proc. - C. 97, 225-230

12. Hong, Y., Liu, C.C.: A Heuristic and Algorithmic Approach to Var Planning. IEEE Trans on Power Syst. 7(2), 505-512 (1992)

13. Iba, K.: Reactive Power Optimization by Genetic Algorithm. IEEE Trans, Power Syst. 9(2), 685-692 (1994)

14. Lee, k.y., Bai, X., Park, Y.M.: Optimization method for reactive power planning by using a modified simple Genetic Algorithm. IEEE Trans on Power Syst. 10(4), 1843-1850 (1995)

15. Miu, K.N., Chiang, H.D., Darling, G.: Capacitor placement, replacement and control in large scale distribution systems by a GA- based two stage Algorithm. IEEE Trans on Power Syst 12(3) (1997)

16. Abdullah, W.N.W., Saibon, H., Zaia, A.A.M., Lo, K.L.: Genetic Algorithm for reactive power Dispatch. IEEE Catalogue No 98EX137, 160-163 (1998)

17. Xiangping, M., Zhishan, L., Huaguang, Z.: Fast synthetic Genetic Algorithm and its application to optimal control of reactive power flow. IEEE 0-7803-4754-4/98, 1454-1458 (1998) 
18. Ghose, T., Goswami, S.K., Basu, S.K.: Solving Capacitor placement problems in Distribution systems using Genetic Algorithms. Electric Machines and Power systems. 27, 429-441 (1999)

19. Mantovani, J.R.S., Modesto, S.A.G., Garcia, A.V.: Var Planning Using Genetic Algorithm and linear programming. IEE Proc, Gener. Transm. Distrib. 148(3), 257-262 (2001)

20. Bakirtzis, A.G., Biskas, P.N., Zoumas, C.E., Petridis, V.: Optimal Power flow by Enhanced Genetic Algorithm. IEEE Trans on Power Syst. 17(2), 229-236 (2002)

21. Wu, O.H., Ma, J.T.: Power System Reactive Power Dispatch Using Evolutionary Programming. IEEE Trans, Power Syst. 10(3), 1243-1248 (1995)

22. Ma, J.T., Lai, L.L.: Evolutionary programming approach to reactive power planning. IEE Proc, Gener. Transm. Distrib. 143(4), 365-370 (1996)

23. Yeh, E.C., Venkata, S.S., Sumic, Z.: Improved Distribution system planning using computational evolution. IEEE Trans on Power Syst. 11(2), 668-674 (1996)

24. Lai, L.L., Ma, J.T.: Application of Evolutionary programming to reactive power planningcomparision with nonlinear approach. IEEE Trans, Power Syst. 12(1), 198-206 (1997)

25. Lee, K.Y., Yang, F.F.: Optimal Reactive Power Planning using Evolutionary Algorithms: A Comparative Study for Evolutionary Programming, Evolutionary strategy, Genetic Algorithm and Linear Programming. IEEE Trans, Power Syst. 13(1), 101-108 (1998)

26. Wong, K.P., Yuryevich, J.: Evolutionary-programming-based Algorithm for environmentally-constrained economic dispatch. 13(2), 301-306 (1998)

27. Gomes, J.R., Saavedra, O.R.: Optimal Reactive Power Dispatch Using Evolutionary Computation: Extended algorithms. IEE Proc, Gener. Transm. Distrib. 146(6), 586-592 (1999)

28. Yoshida, H., Kawata, K., Fukuyama, Y., Takayama, S., Nakanishi, Y.: A Particle Swarm Optimization for Reactive Power and Voltage Control Considering Voltage Security Assessment. IEEE Trans, Power Syst. 15(4), 1232-1239 (2000)

29. Storn, R., Price, K.: Minimizing the real functions of the ICEC' 96 contest by differential evolution. IEEE 0-7803-2902-3/9, 842-844 (1996)

30. Cheng, S.L., Hwang, C.: Optimal Approximations of Linear systems by a Differential Evolution Algorithm. IEEE Trans on Systems, Man and Cybernetics, Part A: Systems and Humans 31(6), 698-707 (2001)

31. Lampinen, J.: A Constraint Handling approach for the Differential Evolution Algorithm. IEEE 0-7803-7282-4/02, 1468-1473 (2002)

32. Su, C.T., Lee, C.S.: Modified Differential Evolution method for capacitor placement of Distribution systems. IEEE 03-7525-4/02, 208-213 (2002)

33. Zhang, W.J., Xie, X.F.: DEPSO: Hybrid particle swarm with differential operator. IEEE 07803-7952-7/03-2003, 3816-3821 (2003)

34. Yan, W., Lu, S., Yu, D.C.: A Novel Optimal Reactive Power Dispatch Method Based on Improved Hybrid Evolutionary Programming Technique. IEEE Trans, Power Syst. 19(2), 913-918 (2004) 